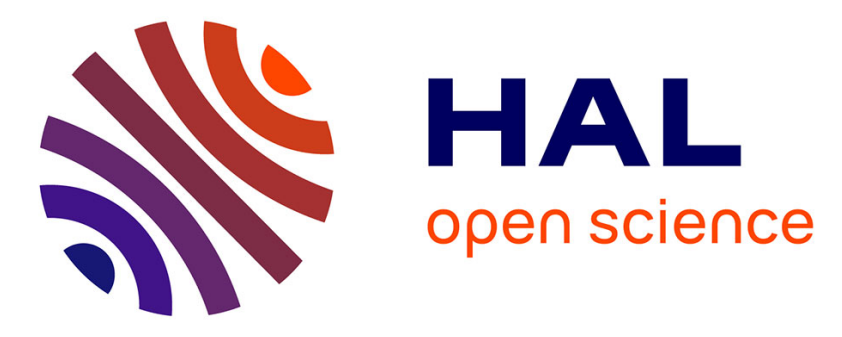

\title{
Digitalizing Occupational Health, Safety and Productivity for the Operator 4.0
}

David Romero, Sandra Mattsson, Åsa Fast-Berglund, Thorsten Wuest, Dominic Gorecky, Johan Stahre

\section{- To cite this version:}

David Romero, Sandra Mattsson, Åsa Fast-Berglund, Thorsten Wuest, Dominic Gorecky, et al.. Digitalizing Occupational Health, Safety and Productivity for the Operator 4.0. IFIP International Conference on Advances in Production Management Systems (APMS), Aug 2018, Seoul, South Korea. pp.473-481, 10.1007/978-3-319-99707-0_59 . hal-02177866

\section{HAL Id: hal-02177866 https://hal.inria.fr/hal-02177866}

Submitted on 9 Jul 2019

HAL is a multi-disciplinary open access archive for the deposit and dissemination of scientific research documents, whether they are published or not. The documents may come from teaching and research institutions in France or abroad, or from public or private research centers.
L'archive ouverte pluridisciplinaire HAL, est destinée au dépôt et à la diffusion de documents scientifiques de niveau recherche, publiés ou non, émanant des établissements d'enseignement et de recherche français ou étrangers, des laboratoires publics ou privés.

\section{(c)(1)}

Distributed under a Creative Commons Attribution| 4.0 International License 


\title{
Digitalizing Occupational Health, Safety and Productivity for the Operator 4.0
}

\author{
David Romero ${ }^{1}$, Sandra Mattsson ${ }^{2}$, Åsa Fast-Berglund ${ }^{2}$, Thorsten Wuest ${ }^{3}$, \\ Dominic Gorecky ${ }^{4}$, Johan Stahre ${ }^{2}$ \\ ${ }^{1}$ Tecnológico de Monterrey, Mexico \\ david.romero.diaz@gmail.com \\ ${ }^{3}$ Chalmers University of Technology, Sweden \\ sandra.mattsson@chalmers.se, asa.fasth@chalmers.se, johan.stahre@chalmers.se \\ ${ }^{4}$ West Virginia University, USA \\ thwuest@mail.wvu.edu \\ ${ }^{5}$ Switzerland Innovation, Switzerland \\ dominic.gorecky@switzerland-innovation.com
}

\begin{abstract}
Industry 4.0 technologies, such as enterprise wearables, can foster better industrial hygiene to keep operators healthy, safe, and motivated within emerging cyber-physical production systems. This paper provides an optimistic perspective on opportunities evolving from wearable devices in an Industry 4.0 workplace environment to support occupational health, safety and productivity for the Operator 4.0. Examples of technical solutions, and their associated application scenarios, are presented showcasing how enterprise wearables may foster detection of situations that involve potential occupational risks before they actually occur at smart shopfloors.
\end{abstract}

Keywords: Industry 4.0, Operator 4.0, Occupational Health \& Safety, Human Cyber-Physical Systems, Human-Automation and Human-Machine Interfaces, Smart Wearables, Socially Sustainable Manufacturing, Industrial Hygiene.

\section{Introduction}

Digitalization, and the paradigm shift associated with it, is shaping the future of work. This specifically includes new challenges and opportunities for occupational health, safety, and productivity for the well-being of the Operator 4.0 [1]. In this context, Industry 4.0 technologies such as enterprise wearables ${ }^{1}$ [2] can foster better industrial hygiene to keep operators healthy, safe, and motivated within emerging smart and social shopfloors [3] [4]. Real-time monitoring of a range of Operator 4.0 vital signs and her/his surrounding workplace environment is currently being facilitated by wearable sensors [5] as well as a sensing and social shopfloor (i.e. ambient intelligence) [3] [4]. This is the basis for the development of Occupational Health and Safety (OHS) applications for [6]: (i) alerting workers of possible exposure to risks factors like toxins, high temperatures, or noise levels; (ii) emergency stops of heavy machinery; (iii) antiergonomic body movements and postures - in order to avoid strain or injury; and/or (iv) monitoring of cognitive and physical workloads to avoid Muri $^{2}$ (overburden).

\footnotetext{
1 e.g. exoskeletons; body-sensors; mixed reality glasses; smart- watches, helmets, handsets; location trackers.

${ }^{2}$ Muri occurs when operators are utilized (overworked) for more than $100 \%$ to finish their tasks.
} 
Discussing real-time monitoring (tracking) of operators generally implies visiting topics such as data related privacy and labour regulations [7]. However, taking an optimistic perspective, and delimiting legal and regulatory matters, wearable trackers (and associated data) have the potential to drive positive changes in smart workplaces.

This paper explores examples of technical solutions, and their associated application scenarios, which could be used as preventive and proactive approaches to enable detection of situations of potential occupational risks before they actually occur at smart shopfloors. This exploration is seen in the context of supporting the Operator 4.0 in her/his daily routines and jobs (i.e. labour polyvalence), considering the operators' cognitive and physical well-being together with the achievement of production objectives, as work complexity may increase within smart shopfloors of the new Industry 4.0 workplace environment.

\section{The Healthy Operator 4.0 and her/his Smart Workplace}

The Operator 4.0 is defined as "a smart and skilled operator who performs not only 'cooperative work' with robots, but also 'work aided' by machines as and if needed. This may be achieved by means of human cyber-physical systems, advanced humanmachine interaction technologies and adaptive automation towards 'human-automation symbiosis work systems" "[1]. The sub-type Healthy Operator 4.0 uses smart wearable solutions (i.e. wearable trackers for health-related metrics) including data analytics capabilities together with advanced Human-Machine (HMI) and Human-Automation Interfacing/Interaction (HAI) technologies, to utilize her/his bio-data (i.e. physiological data). Thus, driving positive change in terms of improved productivity, well-being, and proactive safety measures at smart workplaces [1].

The Healthy Operator 4.0 type emerged within the Operator 4.0 typology [1], in response to rising concerns about increasing workforce stress levels and state of psycho-social health [8] [9]. Further, the Healthy Operator 4.0 concept addresses new potential physical risks [10] [11] in emerging, cyber-physical production environments being 'disrupted' by the introduction of new Industry 4.0 technologies (e.g. autonomous and collaborative robots, augmented reality and virtual reality, artificial intelligence, big data analytics, internet of things, etc.) and new work-methods [12].

In this context, the operators' well-being, incl. OHS, job satisfaction, work-related affect, and workforce productivity [13] has rarely been operationalized in the past due to limitations in measurability of the phenomenon directly and in real-time. This has changed with new smart wearable technologies [14] [15] (with processing, data storage and communication capabilities) and ambient intelligence [15] at the smart shopfloors.

The next sub-sections discuss how the cognitive and physical workload of a Healthy Operator 4.0 can be measured using wearable devices and how the operator can be 'strategically' managed using Artificial Intelligence (AI) to predict and enhance the operator's health. The AI can be included in a Cyber-Physical Production System (CPPS) [16], which comprises both Internet of Things (IoT) and smart applications.

\subsection{Reducing the Operator's Cognitive Workload}

Cognitive load can be defined as a multidimensional construct representing the mental efforts involved in performing a particular task and their effects on the operator's 
cognitive system. Two such constructs are: (i) the causal dimension - reflecting the interaction between task and operator characteristics, and (ii) the assessment dimension - reflecting measurable concepts of mental load, mental effort, and performance [17].

In order to assess (or measure) cognitive workload, this paper adopts the operator's perceived view of her/his workstation considering mental load and performance [18]. The operators perceived view is assessed through perceived production complexity, which is defined as "the interrelations between product variants, work content, layout, tools and support tools and work instructions, as perceived by the operators" [18]. Moreover, Industry 4.0 production lines are characterized by highly- flexible and adaptable manufacturing systems that support mass-customization and personalization strategies. As a result, Industry 4.0 production lines create an increasingly complex production and high-variance working environment for the operator, thus increasing the mental effort required from her/him to perform the tasks [19]. An increase in perceived production complexity is not negative for the operators' health per definition, nevertheless, it is important to study what variable relations affect the increase [18].

One way to cope with production complexity, and therefore support the operator's cognitive workload in her/his daily job, is by means of Smart Cognitive Support Tools $(S C S T)^{3}$ (e.g. augmented reality-based tools and other intelligent HMIs). SCSTs can present information in a more intuitive way to the Operator 4.0 as and if needed. This is enabled by 'AI capabilities' for aided decision-making and understanding of the cognitive task at hand [19] [21] [22]. The SCSTS can also present information in realtime to the operator that is adapted to her/his cognitive load level (e.g. if a disturbance occurs information regarding that is presented to the operator in terms decision support). For example, cognitive workload can be relieved by assessing the operator's well-being at work using smart wearables (i.e. body-sensors for assessing changes in the operator's cognitive states based on skin conductance, blood-pressure, heart-rate, breathing and/or temperature measurements or by assessing eye-movement) [23]. In parallel her/his cognitive-load can be managed by addressing the cognitive tasks allocated to her/his job to keep the operator at an ideal 'stress level', without under- or over-whelming her/him. This could be achieved by associating new variations to an Operator 4.0's routine whose vital data suggest she/he is bored with her/his current routines, or on the other extreme, provide less variety to the Operator 4.0 who is overwhelmed by new tasks, indicated by e.g. perspiration and high-pulse rate.

\subsection{Reducing Operators' Physical Workload}

Physical load - can be defined as the physical effects of mechanical forces on the human body [23]. Furthermore, physical workload can be assessed (or measured) in terms of "biomechanical events occurring in the human body" [23]. Hence, today, wearables can provide a wide range of sensors that measure acceleration, motion and stress (e.g. number of steps, time during day when the operator is standing/sitting, and work-pace), which can be associated with the operators' physical workload. This opens up new opportunities to measure the Operators 4.0 exposure to various mechanical forces in real-time, to always support the practice of proper ergonomics during daily

\footnotetext{
${ }^{3}$ SCSTs are assisting tools that use AI capabilities to leverage innate human abilities, e.g. visual information processing, to improve human understanding and cognition of challenging problems [adapted from 20].
} 
working routine(s). Moreover, smart sensors can be used to increase adaptability between humans and robots in order to create truly collaborative environments.

The Healthy Operator 4.0 aims to provide sustainable solutions for workers through both a personalized design process and customized recommendations of ergonomic work-routines. That way, the operators' health and productivity can be increased in a sustainable fashion. Several theoretical benefits emerge from this development, besides the overall goal of healthier employees: (i) less sick-days, (ii) lower risks of workaccident/injury related law-suites, (iii) better planning of staff availability when operator health can be predicted based on sensory input, and (iv) lower personnel turnovers.

\subsection{HCA, HAI, and HMI as Means to Support Smart Workload Management}

This sub-section introduces relevant enabling means for supporting smart workload management in the factories of the future, taking advantage of new human-centred automation design approaches [24] and human-machine interfaces [25] [26].

Human-Centred Automation (HCA) [24] is defined as "automation designed to work cooperatively with human operators in pursuit of stated objectives". HCA emphasizes that automation functionality should be designed to support human performance and human understanding of the automation system. This means that automation systems must support both cognitive and physical workload of the operator [24]. In order to do this, Human-Automation Interaction (HAI) is needed and is defined as "the way a human controls and receives information from automation" [25]. Automation is then defined as "the execution by a machine agent of a function previously carried out by a human" [26]. Moreover, Human-Machine Interfaces/Interactions (HMI) are defined as interfaces/endeavours that allow user inputs to be translated into signals for machines. They, in turn, provide required results to the user, ranging from knowledge discovery to information visualizations in recent cyber-physical world(s) at 'smart shopfloors'.

In [21] and [3], Romero et al. explore how 'intelligent' HMIs, as well as adaptive and human-in-the-loop control systems (i.e. HAIs) can support the development of Human-Automation Symbiosis (HAS) work systems for the Operator 4.0. HAS work systems aim to offer the Healthy Operator 4.0 the inherent advantages of smart cognitive, physical, and hybrid, automation-aided systems. Such systems can provide sustainable relief of physical and mental stress for the operator, as and if needed. That way, production objectives and productivity goals do not get compromised. Neither does the health and safety of the Operator 4.0 [21].

\section{Digitally-enabled OHS and Enhanced-Productivity Scenarios}

This section explores three examples of scenarios where digitally-enabled OHS and enhanced-productivity solutions support the Healthy Operator 4.0 to stay healthy, safe, and highly-productive in emerging Industry 4.0 manufacturing systems.

\subsection{Smart Exoskeletons in Industry 4.0 Assembly Lines}

Exoskeletons are wearable assistance devices powered by a system of electric motors, pneumatics, levers, hydraulics, or a combination of technologies that allow for limb movement with increased strength and endurance (i.e. physical load) [27]. Smart exoskeletons are a type of exoskeletons that have been instrumented with 'smart on- 
body-sensors' for behavioural and biomechanical modelling with the intention of realtime monitoring and recognition of anti-ergonomic body movements and postures in order to avoid strains or injuries in operators.

From the perspective of a digitally-enabled OHS scenario, smart exoskeletons can help operators to improve their postures and to reduce work-related injuries while performing manual tasks, e.g. when an operator has to lift heavy parts and restrain them into the assembly position. Complementary, from the perspective of an enhancedproductivity scenario, smart exoskeletons can reduce currently required human physical efforts during many manual tasks. Resulting reductions in strenuous and tiring work have the potential to reduce work fatigue and increase operators' productivity.

More generally, any kind of physical activity, such as lifting, pushing, pulling, carrying, moving, manipulating, holding or restraining objects, is considered to be a manual task [28]. Any kind of similar physical activity may cause musculoskeletal disorders (MSDs). MSDs represent a central issue for operators and public health [29]. Hence, smart exoskeletons can identify conditions under which the risk of work-related MSDs is high(er), so that the operator can then either be provided with multimodal (e.g. visual, auditory and tactile) feedback and recommendations in order to change risky or critical postures. Another option is that the exoskeleton intervenes actively and supports the limb movement with supplementary strength and endurance.

The continuous collection of (personal) ergonomic assessment data over time and scale will also help to build-up a comprehensive database of occurring manual tasks and postures. This database enables the system to learn about risky and critical work conditions that can be generalized as new ergonomic guidelines at the same time that will allow the development of adequate interventions for each operator.

\subsection{Adaptive Collaborative Robots (Co-Bots) in Industry 4.0 Assembly Lines}

Adaptive co-bots are collaborative robots that dynamically adapt to the human's pace, stress-level, and experience [30]. Adaptive co-bots can result in co-bots working more efficiently and seamlessly with their human partners, consequently, increasing their overall productivity [30]. From both perspectives, a digitally-enabled OHS and an enhanced-productive scenario, adaptive co-bot systems will monitor the operators' cognitive and physical workloads and work proactively [31] to avoid Muri. This is made possible through available smart wearable body-sensors at the Operator 4.0 measuring skin conductance - using an electro-dermal activity sensor, body-motion using accelerometers and gyroscopes, and/or heart-rate - using a pulse sensor, which will send data to an AI-system that optimises the cognitive and physical help depending on the status of the operator, e.g. pace, stress-level and experience. Hence, an adaptive co-bot will change its speed and number of tasks performed, depending of the operator's health status. More generally, if an operator indicates signs of fatigue (e.g. longer cycle-times or bad quality), an AI-system can take over the tasks while the operator can decrease her/his cognitive and physical workload. When the adaptive cobot receives indication that the operator has recovered, it can start providing the operator with more tasks again. This can even out cycle-time and quality of products, but also decrease sick-leaves related to stress and over-load (e.g. burn-out) of the operators. In addition, the adaptive co-bot will support the operator when she/he needs to do another task (e.g. solving a disruption in the production line). 
Using adaptive co-bots as a supporting element in work-systems, provides the opportunity to adjust the degree of assistance based on a variable automation level [32] and respond to human restrictions individually [33]. Hence, there is little consideration of the operator's individual performance parameters to design her/his workstationorientated to personal capabilities and ergonomics [33] today. More research is needed to fully create collaborative and adaptable workstations for the Healthy Operator 4.0.

\subsection{Smart Personal Protective Equipment in Logistics 4.0 Environments}

The purpose of Personal Protective Equipment (PPE) is to reduce worker exposure to hazards, when engineering and administrative controls are not feasible or effective to reduce such risks to acceptable levels. Present PPEs can be considered as 'passive' protective equipment that aims to reduce the severity of an injury in case of an accident. Nevertheless, and from a perspective of a digitally-enabled OHS scenario, a new generation of Smart PPEs is emerging. These are mainly driven by the development of smart wereables and the arrival of work environmental sensors to the industrial workplaces towards ambient intelligence [15], manifested as smart workplaces, thanks to the measurement of environmental parameters - using temperature, humidity, noise, workplace light, air-quality and/or motion sensors, and of workers' location and vital body functions - using smart wearable body-sensors and location trackers. Such is the case of intelligent container ports where Smart PPEs interact with in motion smart containers and smart cranes to 'actively safeguard' the harbour staff also in motion at the terminal by alerting them of dangerous situations (e.g. walking by accident under a container being lift/transported by a crane).

Overall, Smart PPEs aim to 'actively' prevent and ensure workers health and safety by alerting workers of possible exposure to risks factors like toxins, high temperatures, or noise levels as well as dangerous (smart) objects moving nearby [34]. From the perspective of an enhanced-productivity scenario, Smart PPES can improve operators' productivity by making it easier for the Operators 4.0 to get alerts and communicate with each other thanks to wearable computing (i.e. the Social Operator 4.0 [1]).

\section{Conclusions}

The vision of the Operator 4.0 [1], i.e. the Healthy Operator 4.0, may seem futuristic. Nevertheless, many workers constantly wear personal and private activity trackers, smart watches and other wearables containing micro-gyroscope technology, heart-rate monitoring capability and GPS-positioning functionality. Yet, in today's production environments, productive use of this new abundance of data has not been exploited, neither for the benefit of the workers, nor for corporate reasons. This paper provides an optimistic perspective on future opportunities emerging from 'enterprise wearables' in an Industry 4.0 workplace environment that may soon be realised. Through typical case descriptions, the authors aim to attract the attention of industry management involved in analysing how available resources and technologies can be used to address everyday concerns for worker well-being. In addition, by raising the awareness of such cases some of them might become reality.

While this is intended as a visionary paper, the authors are aware that some of the core limitations are not necessarily technical in nature. Having access to personal data 
and information includes a significant potential for misuse of data - e.g. predicting a worker's health to base a promotion or contract-termination decision on the acquired data. Such legal and ethical topics need urgent public discussion among interdisciplinary groups of experts. Problems should be addressed by experts on philosophy and legal issues as well as on social and humanities matters, in addition to the 'usual line of suspects' from business, computer science, and engineering. In addition, the acceptability of the operators need to be studied. New technologies should always be introduced to the operator in a cooperative manner and the effects of the application of the Healthy Operator 4.0 should be clearly presented.

Forthcoming work involves bringing the illustrated example scenarios to 'life' and carefully evaluating their technological feasibility. First evaluations can be done in a lab setting, for proof-of- concept investigations. Later, assessments should be made with industrial partners in real-world smart shopfloors, to analyse return on investment and potential non-technical issues e.g. employee acceptance.

\section{References}

1. Romero, D., Stahre, J., Wuest, T., Noran, O., Bernus, P., Fast-Berglund, Å., Gorecky, D.: Towards an Operator 4.0 Typology: A Human-Centric Perspective on the Fourth Industrial Revolution Technologies. Int'l. Conf. on Computers \& Industrial Engineering (CIE46) Proceedings, Tianjin/China, pp. 1-11 (2016)

2. Pavón, I., Sigcha, L.F., Arezes, P.M., Costa, N., de Arcas, G, Lopez-Navarro, J.M.: Wearable Technology for Occupational Risk Assessment: Potential Avenues for Applications. Occupational Safety and Hygiene VI, pp.447-452, CRC Press Book (2018)

3. Romero, D., Wuest, T., Stahre, J., Gorecky, D.: Social Factory Architecture: Social Networking Services and Production Scenarios through the Social Internet of Things, Services and People for the Social Operator 4.0. Part I, IFIP AICT 513:265-273 (2017)

4. Kassner, L., Hirmer, P., Wieland, M., Steimle, F., Königsberger, J., Mitschang, B.: The Social Factory: Connecting People, Machines and Data in Manufacturing for Context Aware Exception Escalation. 50th Hawaii Int'1. Conf. on System Sciences (2017)

5. Perera, C., Liu, C.H., Jayawardena, S.: The Emerging Internet of Things Marketplace from an Industrial Perspective: A Survey. IEEE TETEC 3(4):585-598 (2015)

6. Liberty Mutual Insurance by Quartz Creative: Tailor Made to Reduce Risk: Wereables Technology in the Workplace. https://qz.com/1087388

7. Schall, M.C. Jr., Sesek, R.F., Cavuoto, L.A.: Barriers to the Adoption of Wearable Sensors in the Workplace: A Survey of Occupational Safety and Health Professionals. Human Factors, DOI: 10.1177/0018720817753907 (2018)

8. Buffet, M.A., Gervais, R.L., Liddle, M., Eeckelaert, L.: Well-being at Work: Creating a Positive Work Environment. J. of Personality \& Social Psychology, 84(4):822-848 (2013)

9. Salanova, M., Libano, M., Llorens, S., Schaufeli, W.: Engaged, Workaholic, Burned-Out or Just 9-to-5? Towards a Typology of Employee Well-being. Stress Health, 30:71-81 (2014)

10. Matthias, B., Oberer-Treitz, S., Staab, H., Schuller, E., Peldschus, S.: Injury Risk Quantification for Industrial Robots in Collaborative Operation with Humans. 41st Int'l. Symposium on and 6th German Conference on Robotics (ROBOTIK), pp. 1-6 (2010)

11. Vasic, M., Billard, A.: Safety Issues in Human-Robot Interactions. IEEE Int'l. Conf. on Robotics and Automation (ICRA), pp. 197-204 (2013)

12. BCG Boston Consulting Group: https://www.bcg.com/pt-br/publications/2015/technologybusiness-transformation-engineered-products-infrastructure-man-machine-industry-4.aspx

13. Page, K.M., Vella-Brodrick, D.A.: The 'What', 'Why' and 'How' of Employee Well-Being: A New Model. Social Indicators Research, 90(3):441-458 (2009) 
14. Bernal, G., Colombo, S., Al Ai Baky, M., Casalegno, F.: Safety: Designing IoT and Wearable Systems for Industrial Safety through User Centered Design Approach. $10^{\text {th }}$ Int'l. Conf. on Pervasive Technologies Related to Assistive Environment, ACM 163 (2017)

15. Podgorski, D., Majchrzycka, K., Dabrowska, A., Gralewicz, G., Okrasa, M.: Towards a Conceptual Framework of OSH Risk Management in Smart Working Environments based on Smart PPE, Ambient Intelligence and the Internet of Things Technologies. Int'l. J. of Occupational Safety and Ergonomics, 23(1):1-20 (2017)

16. Sameer, M., Muztoba, K., Romero, D., Wuest, T.: Smart Manufacturing: Characteristics, Technologies and Enabling Factors. Journal of Engineering Manufacture (2017)

17. Löscher, I., Axelsson, A., Vännström, J., Jansson, A.: Eliciting Strategies in Revolutionary Design: Exploring the Hypothesis of Predefined Strategy Categories. Theoretical Issues in Ergonomics Science, 19(1):101-117 (2018)

18. Mattsson, S., Tarrar, M., Fast-Berglund, Å.: Perceived Production Complexity: Understanding more than Parts of a System. Int'1. J. of Prod. Res., 54(20): 6008-6016 (2016)

19. Fast-Berglund, A., Stahre, J.: Cognitive Automation Strategy for Reconfigurable and Sustainable Assembly Systems. Assembly Automation, 33(3):294-303 (2013)

20. Walenstein, A.: Foundations of Cognitive Support: Toward Abstract Patterns of Usefulness. 14th Conf. on Design, Specification, and Verification of Interactive Systems (2002)

21. Romero, D.; Bernus, P.; Noran. O.; Stahre, J. and Fast-Berglund, Å.: The Operator 4.0: Human Cyber-Physical Systems \& Adaptive Automation towards Human-Automation Symbiosis Work Systems. IFIP AICT 488, pp. 677-686 (2016)

22. Mattsson, S., Fast-Berglund, Å., Åkerman, M.: Assessing Operator Wellbeing through Physiological Measurements in Real-Time - Towards Industrial Application. Technologies, 5(4):223-232 (2017)

23. Winkel, J., Mathiassen, S.E.: Assessment of Physical Work Load in Epidemiologic Studies: Concepts, Issues and Operational Considerations. Ergonomics, 37(6):979-988 (1994)

24. Billings, C.E.: Aviation Automation: The Search for a Human-Centered Approach (1996)

25. Sheridan, T.B., Parasuraman, R.: Human-Automation Interaction. Reviews of Human Factors and Ergonomics, 1(89):89-129 (2015)

26. Parasuraman, R., Riley, V.: Humans and Automation: Use, Misuse, Disuse, Abuse. Human factors: The Journal of the Human Factors and Ergonomics Society, 39(2):230-253 (1997)

27. Sylla, N., Bonnet, V., Colledani, F., Fraisse, P.: Ergonomic Contribution of ABLE Exoskeleton in Automotive Industry. Int'1. J. of Ind. Ergonomics, 44(4):475-481 (2014)

28. Council for Occupational Safety and Health (COSH): Code of Practice: Manual Tasks. Government of Western Australia, Department of Commerce, Perth (2010)

29. Burgess-Limerick, R.J.: Ergonomics for Manual Tasks. Australian Master of OHS and Environment Guide, CCH Australia, North Ryde, pp. 261-278 (2007)

30. Görür, O., Rosman, B., Sivrikaya, F., Albayrak, S.: Social Cobots: Anticipatory DecisionMaking for Collaborative Robots Incorporating Unexpected Human Behaviors. ACM/IEEE Int'l. Conference on Human-Robot Interaction (2018)

31. Görür, O., Rosman, B., Hoffman, G., Albayrak, S.: Toward Integrating Theory of Mind into Adaptive Decision-Making of Social Robots to Understand Human Intention. Workshop on The Role of Intentions in Human-Robot Interaction (2017)

32. Fasth, Å., Lundholm, T., Mårtensson, L., Dencker, K., Stahre, J.: Designing Proactive Assembly Systems - Criteria and Interaction between Automation, Information, and Competence. CIRP Conference on Manufacturing Systems (2009)

33. Thomas, C., Stankiewicz, L., Grötsch, A., Wischniewski, S., Deuse, J., Kuhlenkötter, B.: Intuitive Work Assistance by Reciprocal Human-Robot Interaction in the Subject Area of Direct Human-Robot Collaboration. Procedia CIRP, Vol. 44, pp. 275-280 (2016)

34. Frost \& Sullivan: Wearables and Smart Personal Protection Equipment (PPE) Technologies for the Industrial Market (2016) 